\title{
Video Article \\ Optimized Staining and Proliferation Modeling Methods for Cell Division Monitoring using Cell Tracking Dyes
}

\author{
Joseph D. Tario Jr. ${ }^{1}$, Kristen Humphrey ${ }^{1}$, Andrew D. Bantly ${ }^{2}$, Katharine A. Muirhead ${ }^{3}$, Jonni S. Moore ${ }^{4}$, Paul K. Wallace ${ }^{1}$ \\ ${ }^{1}$ Department of Flow and Image Cytometry, Roswell Park Cancer Institute \\ ${ }^{2}$ Flow Cytometry \& Cell Sorting Resource Laboratory, University of Pennsylvania \\ ${ }^{3}$ SciGro, Inc. \\ ${ }^{4}$ Department of Pathology and Laboratory Medicine, University of Pennsylvania
}

Correspondence to: Paul K. Wallace at pkw@rpciflow.org

URL: https://www.jove.com/video/4287

DOI: doi:10.3791/4287

Keywords: Cellular Biology, Issue 70, Molecular Biology, Cell tracking, PKH26, CFSE, membrane dyes, dye dilution, proliferation modeling, lymphocytes

Date Published: $12 / 13 / 2012$

Citation: Tario Jr., J.D., Humphrey, K., Bantly, A.D., Muirhead, K.A., Moore, J.S., Wallace, P.K. Optimized Staining and Proliferation Modeling Methods for Cell Division Monitoring using Cell Tracking Dyes. J. Vis. Exp. (70), e4287, doi:10.3791/4287 (2012).

\section{Abstract}

Fluorescent cell tracking dyes, in combination with flow and image cytometry, are powerful tools with which to study the interactions and fates of different cell types in vitro and in vivo. ${ }^{1-5}$ Although there are literally thousands of publications using such dyes, some of the most commonly encountered cell tracking applications include monitoring of:

1. stem and progenitor cell quiescence, proliferation and/or differentiation ${ }^{6-8}$

2. antigen-driven membrane transfer ${ }^{9}$ and/or precursor cell proliferation ${ }^{3,4,10-18}$ and

3. immune regulatory and effector cell function ${ }^{1,18-21}$.

Commercially available cell tracking dyes vary widely in their chemistries and fluorescence properties but the great majority fall into one of two classes based on their mechanism of cell labeling. "Membrane dyes", typified by PKH26, are highly lipophilic dyes that partition stably but non-covalently into cell membranes ${ }^{1,2,11}$. "Protein dyes", typified by CFSE, are amino-reactive dyes that form stable covalent bonds with cell proteins $^{4,16,18}$. Each class has its own advantages and limitations. The key to their successful use, particularly in multicolor studies where multiple dyes are used to track different cell types, is therefore to understand the critical issues enabling optimal use of each class ${ }^{2-4,16,18,24}$.

The protocols included here highlight three common causes of poor or variable results when using cell-tracking dyes. These are:

1. Failure to achieve bright, uniform, reproducible labeling. This is a necessary starting point for any cell tracking study but requires attention to different variables when using membrane dyes than when using protein dyes or equilibrium binding reagents such as antibodies.

2. Suboptimal fluorochrome combinations and/or failure to include critical compensation controls. Tracking dye fluorescence is typically $10^{2}-10^{3}$ times brighter than antibody fluorescence. It is therefore essential to verify that the presence of tracking dye does not compromise the ability to detect other probes being used.

3. Failure to obtain a good fit with peak modeling software. Such software allows quantitative comparison of proliferative responses across different populations or stimuli based on precursor frequency or other metrics. Obtaining a good fit, however, requires exclusion of dead/ dying cells that can distort dye dilution profiles and matching of the assumptions underlying the model with characteristics of the observed dye dilution profile.

Examples given here illustrate how these variables can affect results when using membrane and/or protein dyes to monitor cell proliferation.

\section{Video Link}

The video component of this article can be found at https://www.jove.com/video/4287/

\section{Protocol}

\section{General Membrane Labeling with PKH26 Cell Tracking Dye (Ref. 25; Figure 1)}

1. Use sterile technique for steps $1.1-1.9$. Prepare $\sim 10^{7}$ human peripheral blood mononuclear cells or lymphocytes (hPBMC, $\mathrm{hPBL}$ ) using the laboratory's standard method with addition of a final $300 \times \mathrm{g}$ spin to minimize platelet contamination. Resuspend cells at $10^{7} / \mathrm{ml}$ in $\mathrm{HBSS}+1 \%$ BSA and place on ice, reserving a $500 \mu \mathrm{l}$ aliquot $\left(5 \times 10^{6}\right.$ cells $)$ for use in Step 2.

2. Place $5 \times 10^{6}$ cells $(500 \mu \mathrm{l})$ in a $12 \times 75 \mathrm{~mm}$ conical polypropylene tube. Wash once with $3.5 \mathrm{ml} \mathrm{HBSS}$. Carefully aspirate the supernatant, leaving no more than $15-25 \mu$ l of residual fluid, but taking care not to remove cells. Use this tube to prepare a $2 x$ cell suspension in Step 1.4 
3. During the cell washing in Step 1.2, add $0.5 \mathrm{ml}$ of Diluent $\mathrm{C}$ labeling vehicle (from the PKH26GL kit) to a $12 \times 75 \mathrm{~mm}$ conical polypropylene tube. Use this tube to prepare a $2 x \mathrm{PKH} 26$ solution in Step 1.5.

4. Add $0.5 \mathrm{ml}$ of Diluent $\mathrm{C}$ labeling vehicle to the washed cell pellet from Step 1.2 and aspirate and dispense 3-4 times to obtain a single cell suspension ( $2 x$ cells). Avoid bubble formation and excessive mixing, which may reduce cell viability and recovery.

5. Immediately after preparing the $2 x$ cell suspension in Step 1.4, prepare a $2 x(4 \mu \mathrm{M})$ dye solution by adding $2.0 \mu \mathrm{l}$ of $1.0 \mathrm{mM}$ PKH26 dye stock in ethanol (from the PKH26GL kit) to the Diluent C tube prepared in Step 1.3 and vortex to disperse uniformly.

6. Immediately after preparing the $2 x$ dye solution in Step 1.5 , rapidly pipette the $2 x$ cell suspension from Step 1.4 into the $2 x$ dye solution and simultaneously aspirate and dispense 3-4 times to completely disperse cells in dye. Do not: add $1.0 \mathrm{mM}$ dye directly to cells; pour $2 x$ cells into $2 x$ dye; or add $2 x$ cells to $2 x$ dye while vortexing. Because staining is nearly instantaneous, such methods yield less uniform intensities than the recommended method (Figure 2).

7. After $1 \mathrm{~min}$, add $1.0 \mathrm{ml}$ of heat inactivated serum or HBSS $+5 \%$ BSA to stop dye uptake into cell membranes. Failure to use enough protein risks the formation of dye aggregates, which can pellet with cells during the washing steps and cause unintended labeling of other cells present in an experiment. If medium with $10 \%$ heat inactivated serum (CM) or HBSS $+1 \%$ BSA is to be used as the stop reagent, carry out staining in a $15 \mathrm{ml}$ conical polypropylene tube and add at least $5.0 \mathrm{ml}$ of stop reagent to insure adsorption of all unincorporated dye.

8. Centrifuge the labeled cells for $5 \mathrm{~min} @ \sim 400 \times \mathrm{g}$. Carefully aspirate the supernatant without removing cells. Wash the pellet twice with 4 $\mathrm{ml}$ of $\mathrm{CM}$ or $\mathrm{HBSS}+1 \% \mathrm{BSA}$, dispersing the pellet well before recentrifugation. To minimize carryover of dye adsorbed on tube walls and maximize washing efficiency, transfer the cells to a fresh polypropylene tube after the first resuspension. Note: adequately stained cells will exhibit a distinct pink tinge in the pellet.

9. Resuspend the washed cell pellet in $1.0 \mathrm{ml} \mathrm{HBSS}+1 \%$ BSA. Count the cells, determine cell recovery, and adjust volume to give a final concentration of $10^{7} / \mathrm{ml}$. With careful aspiration, cell recovery should be $\geq 85 \%$. If cell recovery is $<70 \%$, determine the cause before proceeding further. Withdraw a $150 \mu$ l aliquot $\left(1.5 \times 10^{6}\right.$ cells $)$ and place on ice for use in Step 2.

\section{Preparation of Instrument and Assay Setup Controls (Table 1)}

1. Aliquot $50 \mu \mathrm{l}\left(5 \times 10^{5}\right)$ of unstained cells from the cell suspension saved in Step 1.1 into each of five $1.8 \mathrm{ml}$ Eppendorf tubes: $1,3,4,5$, and 7 . Aliquot $50 \mu \mathrm{l}\left(5 \times 10^{5}\right)$ of $\mathrm{PKH} 26^{\mathrm{pos}}$ cells from Step 1.9 into each of three tubes: 2,6 and 8 .

2. Add $10 \mu \mathrm{l} \mathrm{IgG}$ block (100 $\mu \mathrm{g} /$ tube of IgG; see table of Reagents) to Tubes $1-8$ and incubate for 10 min at ambient temperature (20-25 ${ }^{\circ} \mathrm{C}$ ).

3. Add a saturating amount of the antibody(ies) indicated in Table 1 to Tubes 4, 5, 7, and 8 and incubate all samples (Tubes 1-8) for 30 min at ambient temperature and protected from light.

4. Add $1.5 \mathrm{ml}$ of HBSS $+1 \%$ BSA to all samples, pellet the cells by centrifugation ( $5 \mathrm{~min} @ 400 \mathrm{xg}$ ) and wash once with $1.5 \mathrm{ml}$ of $\mathrm{HBSS}+1 \%$ BSA, with careful aspiration to avoid cell loss.

5. Resuspend each sample in $500 \mu$ l of HBSS $+1 \%$ BSA. If required for samples to be analyzed on your cytometer, transfer to a $12 \times 75 \mathrm{~mm}$ round bottom tube. Add $10 \mu \mathrm{l}$ of $100 \mu \mathrm{g} / \mathrm{ml}$ 7-AAD daily working stock (see table of Reagents) to Tubes 3, 6, 7 and 8 as indicated in Table 1 . Incubate on ice for $30 \mathrm{~min}$ prior to use in flow cytometer setup and staining verification (Step 3 ).

\section{Flow Cytometer Setup and Staining Verification}

1. Verify that the flow cytometer is operating properly, using the laboratory's established procedures for daily quality control. Verify that signals can readily be detected in each spectral window to be used, and that detector responses are linearly proportional to signal intensity in the window to be used for proliferation monitoring ${ }^{14}$.

2. Acquire FSC vs. SSC data for Tube 1 using linear display scales. Adjust each detector's amplification such that the lymphocyte population falls in the lower left quadrant of the dot plot, is not off-scale in either parameter, and is not interrupted due to thresholding. Collect ungated FSC vs. SSC data for all samples in Steps $3.3-3.7$.

3. Acquire data for Tube 1, using no color compensation and logarithmic display scales for all 4 fluorescence detectors. Adjust each detector's high voltage (HV) to place the autofluorescence of unstained lymphocytes on scale with few/no cells accumulating in the first channel. Set an analysis boundary for each histogram corresponding to the brightest $2 \%$ of unstained cells.

4. Using no color compensation and the HV settings established in Steps 3.2 and 3.3, acquire data for Tube 2, collecting FSC, SSC and signals in all 4 fluorescence detectors. For the detector used to monitor PKH26 fluorescence, verify that all PKH26 ${ }^{\text {pos }}$ cells appear on scale as a single symmetrical peak in the $3^{\text {rd }}-4^{\text {th }}$ decade, with few/no cells in the last channel. If there are multiple peaks or peak shape is skewed, repeat Step 1 with careful attention to salt minimization and mixing technique (Figure 2). If necessary, adjust dye concentration.

5. Using settings established in Step 3.3, acquire data for Tube 3, collecting FSC, SSC and signals in all 4 fluorescence detectors. For the detector used to monitor 7-AAD fluorescence, verify that 7-AAD ${ }^{\text {pos }}$ cells fall above the $2 \%$ boundary established in Step 3.3 (i.e., that nonviable cells are well resolved from viable $7-A A D^{\text {neg }}$ cells).

6. Using settings established in Step 3.3, acquire data for Tube 4, collecting FSC, SSC and signals in all 4 fluorescence detectors. Verify that CD $8^{\text {pos }}$ cells are well resolved from unstained cells (i.e., fall above the $2 \%$ boundary established in Step 3.3 for the FITC detector). Repeat with Tube 5 and verify that $C D 8^{\text {pos }}$ cells are well resolved from unstained cells (i.e. fall above the $2 \%$ boundary established in Step 3.3 for the APC detector).

7. Using settings established in Step 3.3, acquire data for Tubes 6,7 and 8, collecting FSC, SSC and signals in all 4 fluorescence detectors.

8. Use the list mode files collected for Tubes 1-5 and your color compensation software to establish a color overlap matrix for each fluorochrome in the detectors being used to monitor the three other fluorochromes. Apply this matrix to the list mode file for Sample 6 and verify that the presence of PKH26 labeling does not alter the ability to detect 7-AAD ${ }^{\text {pos }}$ cells.

9. Apply the color overlap matrix from Step 3.8 to the list mode file for Sample 7 and verify that: a) 3 well resolved subpopulations $\left(\mathrm{CD} 3^{\text {neg }} \mathrm{CD} 4^{\text {neg }}, \mathrm{CD}^{\text {pos }} \mathrm{CD} 4^{\text {neg }}\right.$ and $\mathrm{CD} 3^{\text {pos }} \mathrm{CD} 4^{\text {pos }}$ ) can be identified on an FITC vs. APC dot plot; and b) the presence of anti-CD3-FITC and anti-CD4-APC does not alter the ability to detect $7-A A D^{\text {pos }}$ cells. If the presence of anti-CD3-FITC alters the upper $2 \%$ boundary for data collected on the $\mathrm{PKH} 26$ detector, readjust the boundary as required.

10. Apply the color overlap matrix from Step 3.8 to the list mode file for Sample 8 . If the presence of PKH 26 labeling alters the $2 \%$ boundary for the FITC, 7-AAD or APC detectors from those set using the autofluorescence control in Step 3.3, readjust the boundary(ies) as needed using 
Tube 7 of Table 1 and verify that it is still possible to distinguish $C D 3^{\text {pos }} C D 4^{\text {pos }}, \mathrm{CD}^{\text {pos }} C D 4^{\text {neg }}$, and $C D 3^{\text {neg }} C D 4^{\text {neg }}$ cells using the adjusted boundary(ies).

\section{Proliferation Model Selection for Cell Division Monitoring by Dye Dilution}

1. Determine the spacing between generations, which is dependent on the number of channels and logarithmic decades on your cytometer. For digital instruments, this value, typically 4 or 5 decades, is determined by the number of bins in the digital signal processor. On analog instruments, where the number of decades is rarely a whole number, accurate modeling requires the precise number of decades to be experimentally determined. To do this, data from a mixture of calibrated fluorescent beads with manufacturer-assigned relative intensities is acquired at the same detector high voltage settings used in the experiment. The position of the bead peaks allows for the calibration of the logarithmic scale in terms of intensity range per log decade. Specifically, this is done by plotting the channel number for each bead type against the log of the manufacturer-assigned value. The slope of a best-fit straight line for the bead data values gives the number of relative intensity units per channel. Multiplied by the number of channels, this value will then be the number of log decades for the full scale, from which the number of channels corresponding to a two-fold decrease in intensity (i.e., daughter generation spacing) can be calculated ${ }^{14}$.

2. Decide whether to use a fixed spacing between generations or to allow the spacing to float. A Standard (fixed) setting will use the generational spacing value determined in Step 4.5 to assign the location of each generation, and is typically used when the histogram lacks distinct peaks. A Float setting allows each generational peak position to be determined by the histogram shape and is typically used when distinguishable generational peaks are evident.

3. Decide whether to use a fixed peak width for all generations or a floating width. A fixed width uses the SD calculated for the unstimulated control sample to model all generations and is typically chosen when the sample lacks distinguishable generational peaks. A floating width allows the program to independently vary the SD for each generation and is best used with distinguishable generational peaks.

4. Run a program containing a proliferation analysis module (here ModFit LT Version 3.3). Load the stimulated PKH26 $6^{\text {pos }}$ file from the data set to be analyzed (e.g., an stimulated $96 \mathrm{hr}$ culture of $\mathrm{PKH} 26^{\text {pos }}$ cells counterstained as for Tube 8 in Table 1).

5. Select the parameters for analysis, in this case PKH26 (585/42) gated on viable (7-AAD $\left.{ }^{\text {neg }}\right)$ CD ${ }^{\text {pos }}$ lymphocytes and FSC vs. SSC to exclude small debris and large aggregates (Figure 3). In defining these regions be careful to include the high forward scatter area where blasts are typically found and note that CD3 expression may be down-modulated in stimulated cultures.

6. Create a new proliferation model using the Proliferation Wizard. Using the Open Data File (Start tab), load the unstimulated PKH26 ${ }^{\text {pos }}$ control file and define the location of the peak channel in the parental distribution corresponding to undivided cells.

7. Analyze the file for the unstimulated $\mathrm{PKH} 26^{\mathrm{pos}}$ control, noting the values for parental peak position and width (standard deviation). If a fixed peak width (SD) is desired, check Lock $S D$.

8. Load the $\mathrm{PKH} 26^{\text {neg }}$ control (e.g., a $96 \mathrm{hr}$ culture of $\mathrm{PKH} 26^{\text {neg }}$ cells counterstained as for Tube 7 in Table 1). Adjust the number of generations by setting the peak channel for the dimmest generation above the $\mathrm{PKH} 26^{\text {neg }}$ control. This determines the number of daughter generations the model can accurately fit and is typically 6-9 generations.

9. Open the data file for the stimulated sample (e.g., a stimulated $96 \mathrm{hr}$ culture of $\mathrm{PKH} 26^{\text {pos }}$ cells counterstained as for Tube 8 in Table 1 ) and confirm that the regions for the parental peak position and the SD as defined in Step 4.7 remain unchanged. If fixed generational spacing is desired, select Standard model option; otherwise select the Floating option.

10. Analyze each experimental file in the data set, using the same model defined in Step 4.9. Minor adjustments to the parental peak position may be necessary for the very best fit as defined both visually and by the reduced chi square $(R C S)$ value.

11. Record the desired proliferation metrics resulting from the best-fit for each experimental file in the data set. For a comprehensive description of possible metrics see Ref. 22.

\section{Representative Results}

Membrane dyes like PKH26 stain by near-instantaneous partitioning into cell membranes rather than by chemical reaction (for CFSE) or equilibrium binding (for antibodies). Lack of attention to the critical issues outlined in Figure 1 may result in dim or heterogeneous staining of the type shown in Figure 2. In contrast, use of optimized labeling conditions (Figure 1, Table 2) results in bright homogeneous distributions suitable for a variety of cell tracking applications including cell division monitoring based on dye dilution (Figure 3). Dead/dying cells lose varying amounts of tracking dye, which can broaden and/or skew daughter generation intensities and complicate proliferation modeling based on dye dilution $^{3,4,16,18}$. Use of a viability dye is therefore recommended when collecting dye dilution data under conditions where significant numbers of dead cells may be present, such as stimulated cultures (Figure 3) or older specimens (Figure 4).

Because tracking dye labeling typically gives fluorescence intensities several orders of magnitude greater than immunophenotyping, it is important to include appropriate compensation controls (Table 1) and to verify that the presence of tracking dye does not impair ability to resolve antibody positive and negative cells (Figure 4). To avoid the need for excessive color compensation, it is preferable to place a bright fluorochrome, or one not found on cells of interest such as a dye excluded by live cells, in the spectral channel(s) adjacent to the tracking dye (Figure 4A\&B vs. 4C\&D). When using peak modeling software to quantify extent of proliferation, obtaining a good fit requires matching assumptions within the model to the characteristics of the dye dilution profiles being analyzed (Figure $\mathbf{5}$ and Table 3). With appropriate selection of tracking dyes and viability reagents, it is also possible to characterize proliferative responses in multiple lymphocyte subpopulations simultaneously. For example, as illustrated in Figure 6, addition of a 2nd tracking dye simplifies discrimination between regulatory T cells (labeled with CellVue Claret) and highly proliferated effector T cells (labeled with CFSE) and provides much greater detail about their interactions than could be obtained using ${ }^{3} \mathrm{H}$-thymidine labeling ${ }^{18,27}$. 


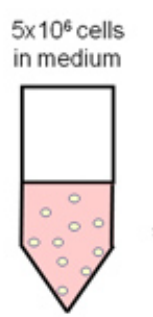

CRITICAL POINTS for $2 X$ cells

- Use healthy cells

- Aspirate carefully to minimize

remaining salts but avoid cell loss

- Disperse cells thoroughly

- Precisely reproduce cell number and diluent volume
$2 X$ cells

Resuspend cells in

$0.5 \mathrm{~mL}$ Diluent $\mathrm{C}$
$2 \mathrm{X}$ dye

Add 2 uL PKH 26 to

$0.5 \mathrm{~mL}$ Diluent $\mathrm{C}$

$1 \times 10^{7}$
cells/mL
$000^{\circ}$
00
0
0

Add $1.0 \mathrm{~mL}$ FBS to stop dye uptake and minimize aggregate formation

Incubate $1 \mathrm{~min}$. at $20-25^{\circ} \mathrm{C}$.

$\downarrow$

$\downarrow$

Wash $2 x$ in 5-10 mL medium+10\% FBS; aspirate carefully to minimize cell loss

Check recovery (>85\%), viability (>90\%), intensity and uniformity of labeling

$\downarrow$

Initiate assay - include positive and negative biological controls to verify unaltered function

Figure 1. General membrane labeling protocol for PKH26, PKH67 and CellVue dyes. Partitioning of these highly lipophilic dyes into cell membranes occurs essentially instantly upon mixing with cells when staining is carried out in the salt-free Diluent $C$ vehicle provided to maximize dye solubility and staining efficiency. As summarized in this schematic for general membrane labeling with PKH26, bright, uniform and reproducible staining is therefore most easily obtained by: 1) minimizing the amounts of protein and/or salts present in the staining step and 2) using a mixing technique that insures rapid homogeneous dispersal of cells in dye (i.e., simultaneously exposes all cells to the same concentration of dye).
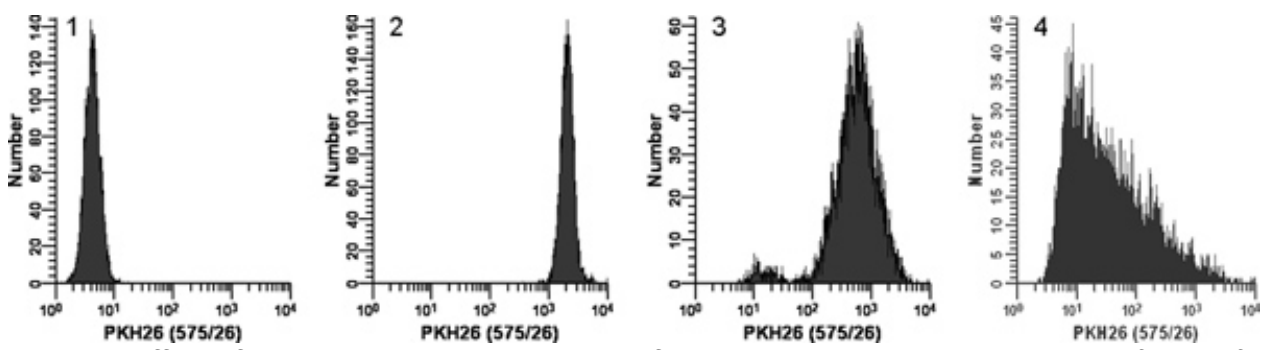

Figure 2. Effect of staining conditions on PKH26 fluorescence distributions (reprinted from Ref. 18). Replicate samples of logarithmically

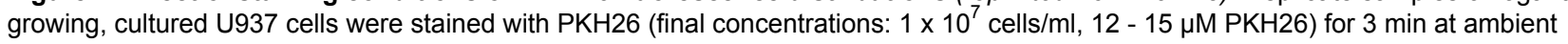
temperature, with or without immediate mixing upon the addition of $2 x$ cells to $2 x$ dye. After washing, stained cells were analyzed on a Beckman Coulter CyAn flow cytometer using constant instrument settings. Histogram 1: unstained control with PKH26 detector voltage adjusted to place all cells on scale in the first decade with few/no cells accumulating in the first channel. Histogram 2: staining at $15 \mu \mathrm{M}$ dye using addition of $2 x$ cells to $2 x$ dye with immediate mixing resulted in a bright, homogenously stained, symmetrical population of cells placed in the fourth decade, with few/no cells accumulating in the last channel ( $\mathrm{gMFI}=2548, \mathrm{gCV}=26.2 \%$ ). Histogram 3 : staining at $15 \mu \mathrm{M}$ dye using addition of $2 \mathrm{x}$ cells to $2 x$ dye but without immediate mixing resulted in a reduced intensity and a broader CV (gMFI $=505, \mathrm{gCV}=116 \%)$ as well as a dimly stained subpopulation, possibly due to a drop of cells dispensed on the wall of the tube rather than into the $2 x$ dye solution. Histogram 4: a staining error led to $3 \mu \mathrm{l}$ of concentrated ethanolic dye stock being added directly to $2 x$ cells in Diluent $C$ without further mixing rather than being used to prepare a $2 x$ dye solution in Diluent $\mathrm{C}$. This resulted in a final dye concentration of $12 \mu \mathrm{M}$ but gave extremely dim and heterogeneous staining ( $\mathrm{gMFI}=32.9, \mathrm{gCV}=1020 \%$ ). The observed right skew most likely reflects the combined effects of: i) poor mixing due to widely disparate cell and dye volumes; and ii) the fact that cells closest to the dye dispensing point would be exposed to a higher concentration of dye than those farther away. Click here to view larger figure. 


\section{A. Unstimulated, 7-AAD viability gate}

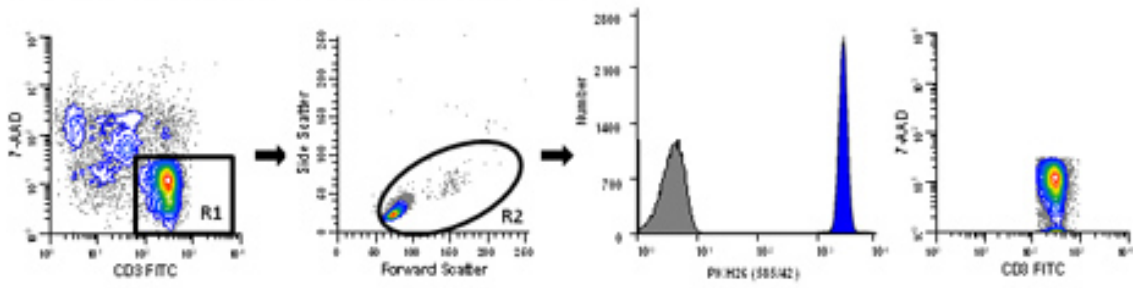

\section{B. Stimulated, 7-AAD viability gate}
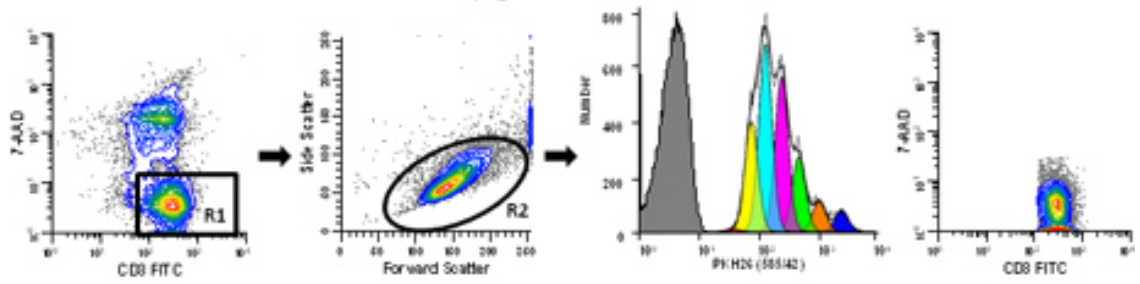

\section{Unstimulated, FSC-SSC viability gate}
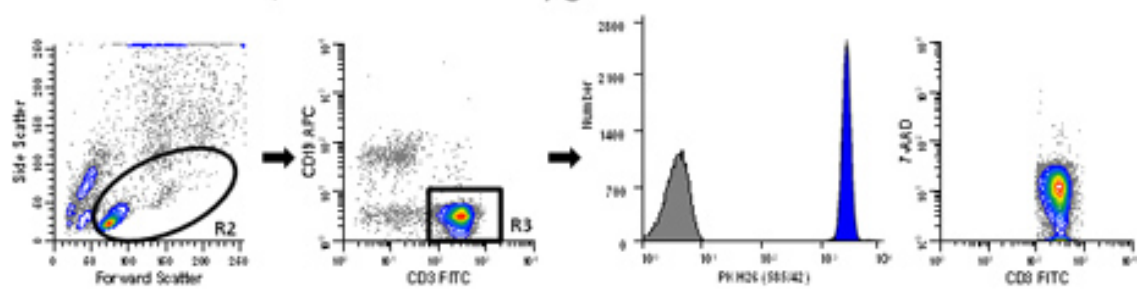

\section{Stimulated, FSC-SSC viability gate}
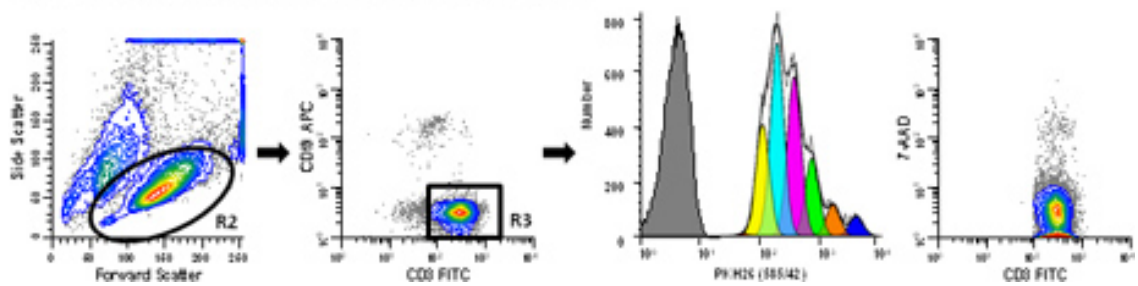

Figure 3. Use of a viability probe simplifies gating of T cell proliferation profiles. hPBMC were labeled with PKH26 (final cell concentration: $3 \times 10^{7} / \mathrm{ml}$; final dye concentration: $10 \mu \mathrm{M}$ ). After culture for $96 \mathrm{hr}$ in the presence (stimulated) or absence (unstimulated) of anti-CD3 and IL-2, cells were counterstained with anti-CD3-FITC, anti-CD19-APC and 7-AAD, and were analyzed on a FACSCalibur flow cytometer (see Reference 13 for details). Color compensation was performed at the time of data acquisition using hardwired compensation circuitry. The extent of proliferation was modeled as described in Step 4 using the Proliferation Wizard in ModFit LT3.3. Data from the PKH26 ${ }^{\text {neg }}$ control (Table 1, Tube 7 ) are overlaid for reference (gray filled histograms in column 3). Viabilities for unstimulated and stimulated cultures were $76 \%$ and $62 \%$ (ungated data for panels A and B, respectively). Panel A. PKH26 stained cells cultured for $96 \mathrm{hr}$ in medium were gated to include viable (7$\left.A A D^{\text {neg }}\right) C D 3^{\text {pos }}$ cells (R1). In addition to the antibody inclusion and 7-AAD dead cell exclusion gate, a forward scatter (FSC) versus side scatter (SSC) gate (R2) was used to exclude debris and aggregates. Note the absence of dead cells in the last plot in this panel. The best fit model for the PKH26 proliferation profile (column 3) gave a single peak with RCS $=2.1$ (Donor 6, Table 3), indicating good symmetry, and was used to define the parental position and starting peak width for analysis of the stimulated sample from this data set (Panel B). Panel B. A replicate aliquot of PKH26 stained cells was cultured with anti-CD3 and IL-2 for $96 \mathrm{hr}$ and gated in the same way as in Panel A. A model with floating peak position and floating peak width gave the best fit for this data with RCS $=1.3$ (Donor 6, Table 3). Panel C. The same data file as in Panel A was analyzed without the use of 7-AAD data. When a primary FSC vs. SSC was used to partially exclude dead cells and aggregates (R2) and a secondary gate to select CD3 positive events (R3), a small residual population of dead cells remained ( $0.2 \%$ of gated events). The best fit model gave a single peak with RCS $=$ 2.2. Panel D. The same data file as in Panel B was gated as in Panel C. Note the larger residual population of dead cells in the stimulated sample (1.29\% of gated events) for this gating strategy. The best fit model was one with floating peak position and floating peak width $(\mathrm{RCS}=1.3)$. Click here to view larger figure. 


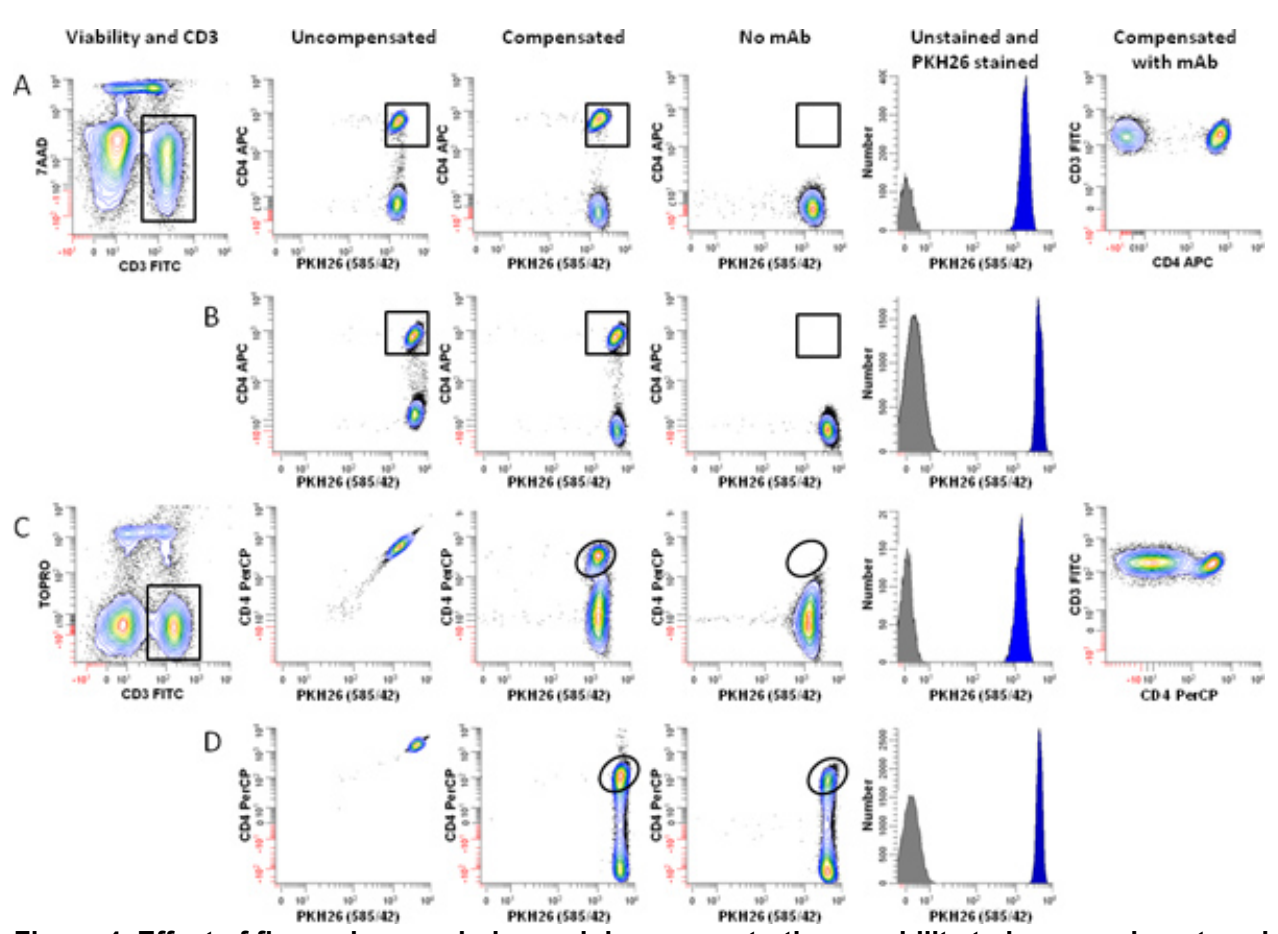

Figure 4. Effect of fluorochrome choice and dye concentration on ability to immunophenotype lymphocytes labeled with PKH26. hPBMC were isolated from 24-hr old blood and labeled with PKH26 as described in Step 1, with the exception that staining was carried out in 12 $x 75 \mathrm{~mm}$ round bottom polystyrene tubes rather than $12 \times 75 \mathrm{~mm}$ conical polypropylene tubes. Immediately after labeling with PKH26, cells were counterstained with the indicated immunophenotypic and viability reagents, and analyzed on an LSRFortessa flow cytometer using the gating strategy of Figure 3A and the following optical configuration: $488 \mathrm{~nm}$ laser: FSC-A (488 nm); SSC-A (488/10 BP), FITC-A (530/30 BP); PKH26A (575/26 BP); 7-AAD-A or PerCP-A (695/40 BP). $640 \mathrm{~nm}$ laser: APC-A or TOPRO-3-A (670/14 BP). Color compensation was performed at the time of data acquisition using BD DiVa software. "Auto" indicates autofluorescence of the no-antibody control in the relevant spectral window (APC for panels A and B, PerCP for Panels $C$ and D). Data from the PKH26 ${ }^{\text {neg }}$ control (Table 1, Tube 7) are overlaid for reference (gray filled histograms, column 5). Post-staining viabilities were similar for all samples (88-92\%). Panel A. Cells labeled with PKH26 at a final concentration of $2 \mu \mathrm{M}$ were counterstained using anti-CD3-FITC, anti-CD4-APC, and 7-AAD (Tube 8 of Table 3). After gating on viable (7-AAD $\left.{ }^{\text {neg }}\right)$ CD $^{\text {pos }}$ lymphocytes (Column 1) and exclusion of debris and aggregates based on FSC and SSC (see Figure 3A), PKH26 intensity was evaluated in combination with APC CD4 (Columns 2 and 3). Whether uncompensated (Column 2) or compensated (Column 3), this fluorochrome combination resulted in good resolution between $\mathrm{CD} 4^{\text {pos }} \mathrm{T}$ cells and CD4 ${ }^{\text {neg }} \mathrm{T}$ cells), as verified both by a no-antibody, autofluorescent control (Tube 6 of Table 1; Column 4) and the two-color plot of CD3 vs. CD4 (Column 6). Panel B. Using the same fluorochrome combination as in Panel A, but increasing the final PKH26 concentration to $4 \mu \mathrm{M}$ did not adversely affect the ability to resolve $\mathrm{CD} 4^{\text {pos }} \mathrm{T}$ cells from CD $4^{\text {neg }} \mathrm{T}$ cells. Panel $\mathrm{C}$. A replicate aliquot of cells independently labeled with PKH26 at a final concentration of $2 \mu \mathrm{M}$ was counterstained using anti-CD3-FITC, anti-CD4PerCP, and TOPRO-3. After gating on viable (TOPRO-3 ${ }^{\text {neg }}$ ) CD3 ${ }^{\text {pos }}$ lymphocytes (Column 1) and exclusion of debris and aggregates based on FSC and SSC (see Figure 3A), PKH26 intensity was evaluated in combination with anti-CD4-PerCP (Columns 2 and 3). Substantial spectral overlap of PKH26 into the PerCP channel is evident in the uncompensated data (Column 2), and resolution between PKH26 $6^{\text {pos }} \mathrm{CD}^{\text {pos }}$ and $\mathrm{PKH} 26^{\text {pos }} \mathrm{CD}^{\text {neg }}$ events is marginal after compensation is applied (compare column 3 with the no-antibody, autofluorescent control shown in Column 4). Panel D. When PKH26 concentration is increased to $4 \mu \mathrm{M}$, it is no longer possible to use the fluorochrome combination of Panel C. Spectral overlap from PKH26 into the PerCP channel exceeds the intensity of the signal from CD4 (Column 2 ) and $\mathrm{CD} 4^{\text {pos }} \mathrm{PKH} 26^{\text {pos }}$ events can no longer be resolved from $\mathrm{CD} 4^{\text {neg }} \mathrm{PKH} 26^{\text {pos }} \mathrm{T}$ cells (Column 3 vs. Column 4). Click here to view larger figure. 
DONOR 5

\section{A. Unstimulated $(96 \mathrm{~h})$}

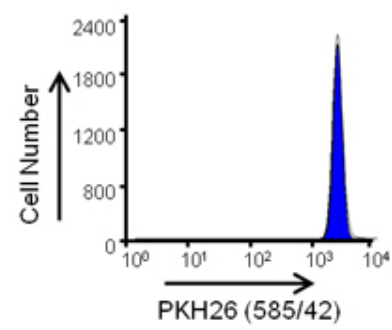

B. Stimulated $(96 \mathrm{~h})$
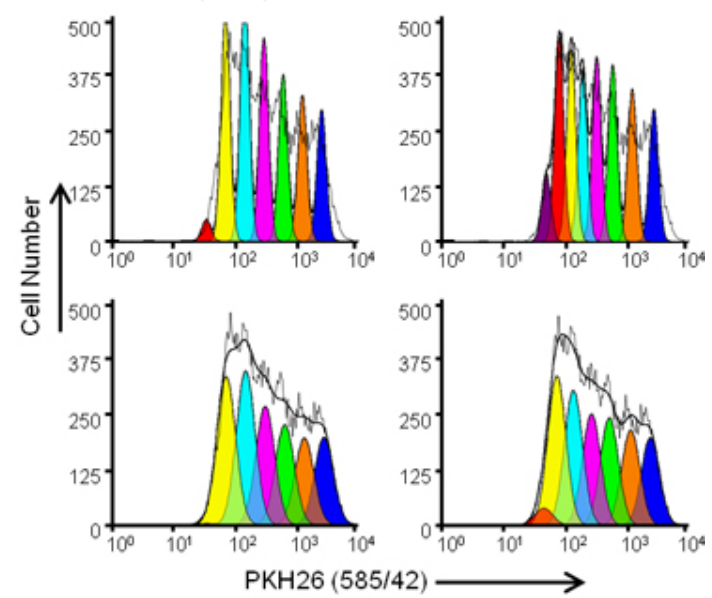

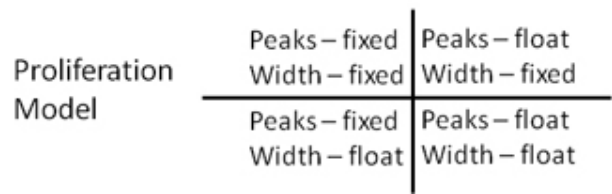

Figure 5. Effect of proliferation model selection on goodness of fit for dye dilution profiles. hPBMC were labeled with PKH26 (final cell concentration: $3 \times 10^{7} / \mathrm{ml}$; final dye concentration: $10 \mu \mathrm{M}$ ). After culture for $96 \mathrm{hr}$ in the presence (stimulated) or absence (unstimulated) of anti-CD3 and IL-2, cells were harvested counterstained with anti-CD3-FITC, anti-CD19-APC and 7-AAD and analyzed on a FACSCalibur flow cytometer (see Reference 13 for detailed methods). Color compensation was performed at the time of data acquisition using hardwired compensation circuitry. Panel A. The PKH26 intensity profile from an unstimulated $96 \mathrm{hr}$ culture for Donor 5, a moderate responder, was gated as shown in Figure 3A and used to provide the ModFit Proliferation Wizard with a first estimate of position and width for the peak representing undivided parental cells. Panel B. The PKH26 intensity profile from a parallel stimulated $96 \mathrm{hr}$ culture was analyzed using the starting estimates from Panel A and 4 different combinations of 'Proliferation Wizard' settings, corresponding to fixed or floating peak intensities, and fixed or floating peak widths for successive daughter generations as shown. As summarized in Table 3, the model that gave the best fit to the observed data (lowest reduced chi-square; RCS) was the "floating/floating" combination in which not only peak positions but also standard deviations of daughter generation peaks were allowed to vary $(\mathrm{RCS}=1.5)$. The same model gave the best fit for Donor 6 , a high responder (Figure $\mathbf{3 B}$ and Table 3). 
A. Treg:Teff $0.25: 1$
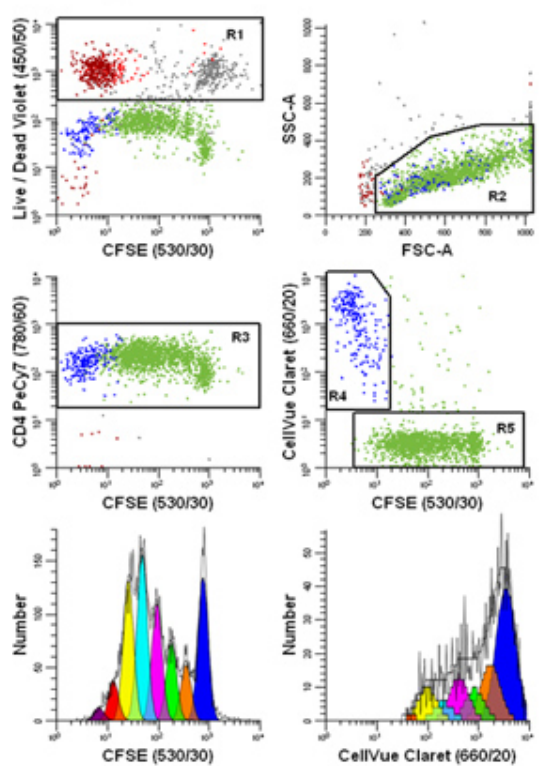

B. Teff proliferation

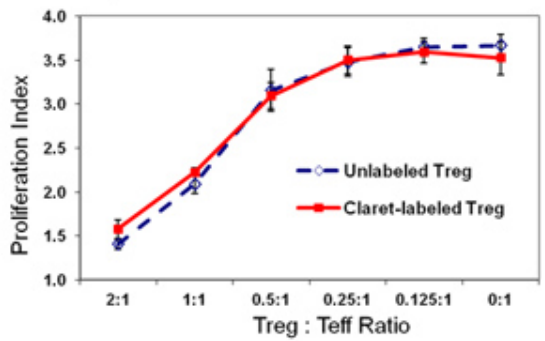

C. Treg proliferation

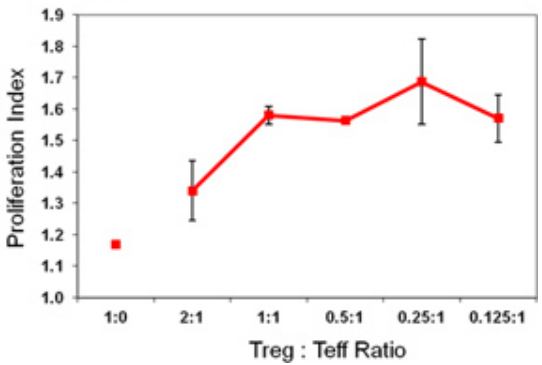

Figure 6. Addition of a second cell tracking dye simplifies discrimination between effector and regulatory T cells in a flow cytometric suppression assay (adapted from Ref. 18). Monocyte-depleted lymphocytes prepared from TRIMA leukapheresis filters were stained with antiCD127-PE, anti-CD4-PE-Cy7, and anti-CD25-APC and flow sorted into populations of effector (Teff; CD4 ${ }^{\text {pos }}$ CD127 $7^{\text {bright }}$ CD25 $5^{\text {dim }}$ ), regulatory (Treg; CD4 ${ }^{\text {pos }} \mathrm{CD} 127^{\mathrm{dim}} \mathrm{CD} 25^{\mathrm{pos}}$ ), and accessory $\left(\mathrm{CD} 4^{\text {neg }}\right.$ ) cells. Sorted Treg cells labeled with CellVue Claret (final cell concentration: $1 \times 10^{6} /$ $\mathrm{ml}$; final dye concentration: $1 \mu \mathrm{M}$ ) and sorted Teff labeled with CFSE (final cell concentration: $5 \times 10^{7} / \mathrm{ml}$; final dye concentration, $5 \mu \mathrm{M}$ ) were co-cultured at varying ratios in the presence of anti-CD3, anti-CD28 and irradiated accessory cells. After $96 \mathrm{hr}$, cultures were harvested, counterstained with anti-CD4-PE-Cy7 and LIVE/DEAD Fixable Violet, and analyzed on an LSRII flow cytometer and color compensation was performed at the time of data acquisition using BD DiVa software (see Reference 18 for details including compensation controls). The Proliferation Indices for Teff and Treg were modeled as described in Step 4, using the Proliferation Wizard in ModFit LT3.3. Data points in panels $\mathrm{B}$ and $\mathrm{C}$ represent the mean \pm 1 standard deviation of triplicate samples. Panel A. Representative data are shown for one of three triplicate samples at a Treg:Teff ratio of 0.25:1. LIVE/DEAD Fixable Violet reagent was used to exclude dead cells (R1, upper left plot; accessory cells $=$ red-brown, nonviable Teff $=$ gray and nonviable Treg $=$ red) from all other data plots. CellVue Claret staining was used to distinguish viable Treg (R4, center right plot; blue) from viable but highly proliferated Teff (R5, center right plot; green). A single parameter CFSE proliferation profile for Teff (lower left plot) was generated by gating on cells that were CFSE ${ }^{\text {pos }}(R 5), C^{2} 4^{\text {pos }}(R 3)$, viable (not R1), and had lymphocyte scatter properties (R2). A single parameter CellVue Claret proliferation profile for Treg was generated by gating on cells that were CellVue Claret $^{\text {pos }}$ (R4), CD4 ${ }^{\text {pos }}$ (R3), viable (not R1), and had lymphocyte scatter properties (R2). Note the generous lymphocyte region (R2) defined to include lymphocyte blasts. Note also that total number of cells to be collected depends upon the lowest frequency population of interest. In a cell proliferation experiment where the population of interest may be distributed over a broad range of intensities representing up to seven or eight generations a large number of cells should be collected in order to accurately model and calculate the number of cells in each generation. When studying rare cells, it may be necessary to simply run the sample tube nearly dry in order to collect the maximum possible number of events. For the sample shown here, doing this resulted in a total of $\sim 25,000$ events, of which 11,923 were Teff (Proliferation Index 3.85 ) and 1,380 were Treg (Proliferation Index 1.83). Panel B. As expected, increasing the proportion of Tregs present in co-cultures led to greater suppression of Teff cell proliferation. Similar results were obtained with both CellVue Claret-stained (solid line) or unstained (dashed line) Treg, indicating that staining with the CellVue Claret tracking dye did not affect Treg potency. Panel C. Treg are relatively anergic and, as expected, did not proliferate when incubated with anti-CD3, anti-CD28, and accessory cells in the absence of Teff cells (Treg:Teff ratio of 1:0). However, as the proportion of Teff present in co-cultures increased (i.e., as the Treg:Teff ratio decreased), the extent of Treg proliferation also increased. The generally larger error bars for these data at least in part reflect the limited extent of proliferation, leading to smaller numbers of events collected relative to Teff and greater uncertainty in modeling the number of cells in each generation. Click here to view larger figure.

\begin{tabular}{|l|l|l|l|}
\hline Tube No. (Purpose) & PKH26 & Antibody(ies) & 7-AAD \\
\hline 1 (Setup, compensation) & - & - & - \\
\hline 2 (Setup, compensation) & + & - & - \\
\hline 3 (Setup, compensation) & - & - & + \\
\hline 4 (compensation) & - & CD8-FITC & - \\
\hline 5 (compensation) & - & CD8-APC & - \\
\hline 6 (no Ab control) & + & - & + \\
\hline 7 (no tracking dye control) & - & $\begin{array}{l}\text { CD3-FITC CD4-APC or CD19- } \\
\text { APC }\end{array}$ & + \\
\hline
\end{tabular}


8 (T0 control)

\begin{tabular}{l}
$\begin{array}{l}\text { CD3-FITC CD4-APC or CD19- } \\
\text { APC }^{c}\end{array}+$ \\
\hline
\end{tabular}

Table 1. Instrument Setup Controls ${ }^{\text {a }}{ }^{\text {a }}$ Controls listed are appropriate for a 4-color CD4 T cell proliferation monitoring assay using: PKH26 (proliferation dye), CD3-FITC (pan-T cell marker), CD4-APC (T-helper cell marker), 7-aminoactinomycin D (7-AAD; dead cell exclusion). ${ }^{b}$ Brighter surrogates for CD3-FITC and CD4-APC (better ability to detect compensation errors). ${ }^{\mathrm{C}}$ Figure 3: CD3-FITC and CD19-APC. ${ }^{d}$ Figure 4: CD3-FITC and CD4-APC

\begin{tabular}{|c|c|c|c|}
\hline Cell type & Final Cell Concentration & Final Dye Concentration & Reference \\
\hline \multirow[t]{7}{*}{$\mathrm{hPBMC}^{\mathrm{b}}$} & $1 \times 10^{7} / \mathrm{ml}$ & $2 \mu \mathrm{M}$ PKH67 & 10,17 \\
\hline & $5 \times 10^{6} / \mathrm{ml}$ & $2 \mu \mathrm{M}$ PKH26 & 12 \\
\hline & $3 \times 10^{7} / \mathrm{ml}$ & $10 \mu \mathrm{M}$ PKH26 & 13 \\
\hline & $5 \times 10^{7} / \mathrm{ml}$ & $30 \mu \mathrm{M}$ PKH26 & 18 \\
\hline & $1 \times 10^{6} / \mathrm{ml}$ & $1 \mu \mathrm{M}$ CellVue Claret ${ }^{\mathrm{c}}$ & 18 \\
\hline & $3 \times 10^{7} / \mathrm{ml}$ & $4 \mu \mathrm{M}$ CellVue Claret & 13 \\
\hline & $5 \times 10^{7} / \mathrm{ml}$ & $5 \mu \mathrm{M}$ CellVue Claret & 18 \\
\hline \multirow[t]{6}{*}{ Cells in culture } & $5 \times 10^{5} / \mathrm{ml}$ & $0.1 \mu \mathrm{M}$ PKH $26\left(1^{\circ} \mathrm{mammary}\right.$ cells $)$ & 8 \\
\hline & $1 \times 10^{7} / \mathrm{ml}$ & 15 M PKH26 (U937) & 18 \\
\hline & $1 \times 10^{7} / \mathrm{ml}$ & 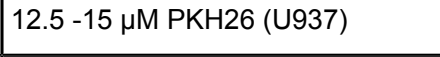 & 15 \\
\hline & $1 \times 10^{7} / \mathrm{ml}$ & $1 \mu \mathrm{M}$ PKH67 (K562) & 18 \\
\hline & $1 \times 10^{7} / \mathrm{ml}$ & $1 \mu \mathrm{M}$ PKH67 ( $\mathrm{T}$ cell lines) & 9 \\
\hline & $1 \times 10^{7} / \mathrm{ml}$ & $10 \mu \mathrm{M}$ CellVue Claret (YAC-1) & 23 \\
\hline
\end{tabular}

Table 2. Non-Perturbing Membrane-Dye Staining Conditions ${ }^{a}$. ${ }^{a}$ Adapted and updated from Ref. $18 .{ }^{b}$ A low speed wash (300 $\mathrm{x}$ ) was used to minimize platelet contamination. ${ }^{\mathrm{c}}$ Treg cells (flow sorted $\mathrm{CD} 4{ }^{\mathrm{pos}} \mathrm{CD} 25^{\mathrm{pos}} \mathrm{CD} 127^{\text {neg }}$ lymphocytes).

\begin{tabular}{|c|c|c|c|c|c|c|c|c|c|}
\hline \multirow[b]{2}{*}{ Donor } & \multirow[b]{2}{*}{ Treatment } & \multicolumn{2}{|c|}{ Model Settings } & \multicolumn{6}{|c|}{ Model Results } \\
\hline & & \begin{tabular}{|l|} 
Peak \\
Position
\end{tabular} & SD & \begin{tabular}{|l|} 
Parental \\
Position
\end{tabular} & Parental SD & $\begin{array}{l}\text { \# of Peaks } \\
\text { Fitted }\end{array}$ & RCS & PI & PF \\
\hline 5 & Unstimulated & Float & Float & 209 & 4.5 & 1 & 5.1 & 1.0 & 0 \\
\hline 5 & Stimulated & Fixed & Fixed & 209 & 4.5 & 7 & 35 & 3.9 & 31 \\
\hline 5 & Stimulated & Float & Fixed & 209 & 4.5 & 8 & 19 & 4.3 & 30 \\
\hline 5 & Stimulated & Fixed & Float & 209 & 9.2 & 6 & 1.9 & 3.8 & 30 \\
\hline 5 & Stimulated & Float & Float & 209 & 9.0 & 7 & 1.5 & 3.7 & 29 \\
\hline 6 & Unstimulated & Float & Float & 205 & 4.0 & 1 & 2.1 & 1.0 & 0 \\
\hline 6 & Stimulated & Fixed & Fixed & 205 & 4.0 & 6 & 42 & 6.6 & 60 \\
\hline 6 & Stimulated & Float & Fixed & 205 & 4.0 & 7 & 12 & 7.4 & 60 \\
\hline 6 & Stimulated & Fixed & Float & 205 & 8.6 & 6 & 6.9 & 6.8 & 62 \\
\hline 6 & Stimulated & Float & Float & 205 & 6.5 & 6 & 1.3 & 6.5 & 59 \\
\hline
\end{tabular}

Table 3. Impact of Proliferation Model on Goodness of Fit (RCS) and Proliferation Metrics ${ }^{\text {a }}$. Sample staining, data collection and gating as described in Figure 3A \& B.

\section{Discussion}

The methods described here are those found in our combined laboratories to most reliably give optimal results for hPBMC labeling using membrane dyes ${ }^{13,16,18}$ and for lymphocyte subset phenotyping and proliferation tracking using either membrane or protein dyes ${ }^{2,11,13,16,18}$. As illustrated in Figures 1 and 2, bright uniform labeling is most readily achieved by limiting the presence of physiologic salts and using a mixing technique that results in rapid, homogeneous exposure of all cells to the same concentration of dye. Because staining with membrane dyes occurs by partitioning into the lipid bilayer, other variables that alter free dye concentration can also impact labeling efficiency. For example, labeling in round bottom polystyrene tubes results in less efficient washout of salts prior to resuspension in Diluent $\mathrm{C}$ and also in reduced free dye concentration due to dye adsorption on tube walls, particularly at lower dye concentrations. Both factors tend to give broader staining distributions than when labeling is done using conical bottom polypropylene tubes (Figures 3, 4 and unpublished results). Sample age and 
type can also affect peak width even when optimized staining procedures are used. For example, CVs for PKH26 ${ }^{\text {pos }}$ lymphocytes isolated from freshly drawn blood range from 14-20\% (Figure 3, Ref. 13 and unpublished results) whereas CVs for lymphocytes isolated from 24 hr old blood samples or TRIMA pheresis filters range from $25-30 \%$ (Figure 4 and Ref. 18).

Staining uniformity and the extent to which non-viable cells can be excluded from analysis both affect whether distinguishable daughter peaks are evident in the dye dilution profile, which in turn affects choice of a proliferation model to fit the observed data (Figures $\mathbf{5}$ and $\mathbf{6}$ ). Although ModFit (Verity Software House, Topsham, ME) is used here as an example of software used to generate metrics such as Proliferation Index and Precursor Frequency (Figures 3, 5 and 6; Table 3), other software packages also contain modules to analyze proliferation data. These include FCSExpress (De Novo Software, Los Angeles, CA) and FlowJo (Tree Star, Inc., Ashland, OR). All of these programs use a non-linear least squares analysis to iteratively find the best fit to the raw data by changing the position, height and SD (or width) of Gaussian peaks representing sequential daughter generations. Proliferative Index (PI) and Precursor Frequency (PF) are the most commonly used measures of extent of proliferation. PI, as defined by ModFit, is a measure of the increase in cell number over the course of the assay, analogous to the 'stimulation index' of a thymidine uptake assay. PF returns the fraction of cells in the initial population that responded to the stimulus by proliferating. Caution is advised, however, when reading the literature since terminology varies somewhat among software packages (e.g., FlowJo and ModFit use different definitions and calculations for what is meant by "Proliferation Index") ${ }^{22}$

The critical issues discussed here for labeling and proliferation analysis with membrane dyes are also encountered when using protein dyes. For example, careful attention to mixing technique must also be observed, along with exclusion of dead/dying cells, in order to obtain uniform distributions and distinguishable daughter peaks when using CFSE (Figure 6) $)^{2-4,13,18,24}$. Appropriate choice of fluorochromes for phenotyping and viability assessment is also important to avoid excessive spectral overlap and inability to recognize antibody positive cells, particularly with visible emitting protein dyes such as $\mathrm{CFSE}^{2-4,11,13,16,18}$. Reducing the concentration of tracking dye decreases compensation problems in adjacent spectral channels but also limits the number of cell divisions that can be monitored before daughter cell intensities begin to overlap with autofluorescence. Alternatively, use of newer cell tracking dyes such as the far red emitting CellVue Claret (Sigma-Aldrich, St. Louis, MO) or violet emitting CellTrace Violet (Life Technologies, Grand Island, NY) may reduce compensation problems (Figure 6). Finally, although membrane dyes generally tend to exhibit less toxicity ${ }^{11,26}$, it is possible to over-label cells with either class of dye. It is therefore always necessary to verify that the concentration of tracking dye used has not altered the functionality of the cells to be tracked (Figure 6) ${ }^{3,13,16,18}$

\section{Disclosures}

K. Humphrey, J.D. Tario, Jr. and P.K. Wallace have received pre-commercial cell tracking reagents for evaluation from Life Technologies, Inc. and BD Biosciences. A.D. Bantly and J.S. Moore have received pre-commercial cell tracking reagents for evaluation from Life Technologies, Inc. and funding from PTI Research, Inc. for pre-commercial characterization of various CellVue cell tracking dyes. K. Muirhead is employed by SciGro, Inc., which provides consulting services to Phanos Technologies, Inc. (owner of the PKH and CellVue dyes) and provides backup technical support for Sigma-Aldrich and Molecular Targeting Technologies, Inc. (distributors of these dyes).

Production and Free Access to this article is sponsored by Sigma-Aldrich.

\section{Acknowledgements}

The authors would particularly like to thank the following individuals for their technical and intellectual contributions to the development of these methods through the years: Bruce Bagwell (Verity Software House), Nadège Bercovici (IDM), Lizanne Breslin (Zynaxis Cell Science and PTI Research), Brian Gray (PTI Research), Jan Fisher (Dartmouth Medical School), Alice Givan (Dartmouth Medical School), Betsy Ohlsson-Wilhelm (SciGro, Inc.), and Mary Waugh (Dartmouth Medical School). They would also like to thank the Bowdoin class of 2006 from the Annual Courses in Research Methods and Applications of Flow Cytometry, which generated the data shown in Figure 2.

Flow cytometry was performed at Roswell Park Cancer Institute's Flow Cytometry Laboratory, which was established in part by equipment grants from the NIH Shared Instrument Program, and receives support from the Core Grant (5 P30 CA016056-29) from the National Cancer Institute to the Roswell Park Cancer Institute, and at the Abramson Cancer Center Flow Cytometry and Cell Sorting Resource Laboratory of the University of Pennsylvania, which was established in part by equipment grants from the NIH Shared Instrument Program, and receives support from NIH \#2P30 CA016520 from the National Cancer Institute. The work shown in Figures $\mathbf{3}$ and $\mathbf{5}$ was also supported in part by SBIR grant EB00228 from the National Institutes of Biomedical Imaging and Bioengineering (NIBIB) awarded to PTI Research, Inc.

\section{References}

1. Poon, R.Y., Ohlsson-Wilhelm, B.M., Bagwell, C.B., \& Muirhead, K.A. Use of PKH Membrane Intercalating Dyes to Monitor Cell Trafficking and Function. In: Living Color: Flow Cytometry and Cell Sorting Protocols., Diamond, R.A. \& DeMaggio, S., eds., Springer-Verlag, New York, NY, 302-352 (2000).

2. Wallace, P.K. \& Muirhead, K.A. Cell Tracking 2007: A Proliferation of Probes and Applications. Immunol. Invest. 36, 527-562 (2007).

3. Hawkins, E.D., Hommel, M., Turner, M.L., Battye, F.L., Markham, J.F., \& Hodgkin, P.D. Measuring lymphocyte proliferation, survival and differentiation using CFSE time-series data. Nat. Protoc. 2, 2057-2067 (2007).

4. Quah, B.J., Warren, H.S., \& Parish, C.R. Monitoring lymphocyte proliferation in vitro and in vivo with the intracellular fluorescent dye carboxyfluorescein diacetate succinimidyl ester. Nat. Protoc. 2, 2049-2056 (2007).

5. Bolton, D.L., Minang, J.T., Trivett, M.T., Song, K., Tuscher, J.J., Li, Y., Piatak, Jr., M., O'Connor, D., Lifson, J.D., Roederer, M., \& Ohlen, C. Trafficking, Persistence, and Activation State of Adoptively Transferred Allogeneic and Autologous Simian Immunodeficiency Virus-Specific CD8+ T Cell Clones during Acute and Chronic Infection of Rhesus Macaques. J. Immunol. 184, 303-314 (2010).

6. Juopperi, T.A. \& Sharkis, S.J. Isolation of Quiescent Murine Hematopoietic Stem Cells by Homing Properties. Meth. Mol. Biol. 430, 21-30 (2008). 
7. Kusumbe, A.P. \& Bapat, S.A. Cancer stem cells and aneuploid populations within developing tumors are the major determinants of tumor dormancy. Cancer Res. 69, 9245-53 (2009).

8. Pece, S., Tosonim, D., Confalonieri, S., Mazzarol, G., Vecchi, M., Ronzoni, S., Bernard, L., Viale, G., Pelicci, P.G., \& Di Fiore, P.P. Biological and Molecular Heterogeneity of Breast Cancers Correlates with Their Cancer Stem Cell Content. Cell. 140, 62-73 (2010).

9. Gertner-Dardenne, J., Poupot, M., Gray, B.D., \& Fournié, J.-J. Lipophilic fluorochrome trackers of membrane transfers between immune cells. Immunol. Invest. 36, 665-685 (2007).

10. Bercovici, N., Givan, A.L., Waugh, M.G., Fisher, J.L., Vernel-Pauillac, F., Ernstoff, M.S., Abastado, J.P., \& Wallace, P.K. Multiparameter precursor analysis of T-cell responses to antigen. J. Immunol. Methods. 276, 5-17 (2003).

11. Givan, A.L., Fisher, J.L., Waugh, M.G., Bercovici, N., \& Wallace, P.K. Use of cell-tracking dyes to determine proliferation precursor frequencies of antigen-specific T cells. Methods Mol. Biol. 263, 109-24 (2004).

12. Schwaab, T., Tretter, C.P., Gibson, J.J., Cole, B.F., Schned, A.R., Harris, R., Fisher, J.L., Crosby, N., Stempkowski, L.M., Heaney, J.A., \& Ernstoff, M.S. Tumor-related immunity in prostate cancer patients treated with human recombinant granulocyte monocyte-colony stimulating factor (GM-CSF). Prostate. 66 (6), 667-674 (2006).

13. Bantly, A.D., Gray, B.D., Breslin, E., Weinstein, E.G., Muirhead, K.A., Ohlsson-Wilhelm, B.M., \& Moore, J.S. CellVue Claret, a New Far-Red Dye, Facilitates Polychromatic Assessment of Immune Cell Proliferation. Immunol. Invest. 36, 581-605 (2007).

14. Givan, A.L. A flow cytometric assay for quantitation of rare antigen-specific T-cells: using cell-tracking dyes to calculate precursor frequencies for proliferation. Immunol. Invest. 36, 563-580 (2007).

15. Tario, J.D., Jr., Gray, B.D., Wallace, S.S., Muirhead, K.A., Ohlsson-Wilhelm, B.M., \& Wallace, P.K. Novel lipophilic tracking dyes for monitoring cell proliferation. Immunol Invest. 36, 861-885 (2007).

16. Wallace, P.K., Tario, Jr. J.D., Fisher, J.L., Wallace, S.S., Ernstoff, M.S., \& Muirhead, K.A. Tracking Antigen-Driven Responses by Flow Cytometry: Monitoring Proliferation by Dye Dilution. Cytometry. 73A, 1019-1034 (2008).

17. Barth, R.J., Fisher, D.A., Wallace, P.K. Channon, J.Y., Noelle, R.L., Gui, J., \& Ernstoff, M.S. A Randomized Trial of Ex vivo CD40L Activation of a Dendritic Cell Vaccine in Colorectal Cancer Patients: Tumor-Specific Immune Responses Are Associated with Improved Survival. Clin. Cancer Res. 16, 5548-5556 (2010).

18. Tario, J.D., Jr., Muirhead, K.A., Pan, D., Munson, M., \& Wallace, P.K. Tracking Immune Cell Proliferation and Cytotoxic Potential Using Flow Cytometry. Meth. Mol. Biol. 699, 119-164 (2011).

19. Fuse, S. \& Underwood, E. Simultaneous Analysis of In Vivo CD8+ T Cell Cytotoxicity Against Multiple Epitopes using Multicolor Flow Cytometry. Immunol. Invest. 36, 829-845 (2007).

20. Schütz, C., Fleck, M., Mackensen, A., Zoso, A., Halbritter, D., Schneck, J.P., \& Oelke, M. Killer artificial antigen-presenting cells: a novel strategy to delete specific T cells. Blood. 111, 3546-3552 (2008).

21. Zaritskaya, L., Shurin, M.R., Sayers, T.J., \& Malyguine, A.M. New flow cytometric assays for monitoring cell-mediated cytotoxicity. Expert Rev. Vaccines. 9, 601-616 (2010).

22. Roederer, M. Interpretation of cellular proliferation data: Avoid the panglossian. Cytometry. 79A, 95-101 (2011).

23. Personal communication, E. Breslin (Zynaxis Cell Science, Inc.).

24. Quah, B.J.C. \& Parish, C.R. The Use of Carboxyfluorescein Diacetate Succinimidyl Ester (CFSE) to Monitor Lymphocyte Proliferation. J. Vis. Exp. (44), e2259, doi:10.3791/2259 (2010).

25. http://www.sigmaaldrich.com/etc/medialib/docs/Sigma/Bulletin/mini26bul.Par.0001.File.tmp/mini26bul.pdf (Sigma product bulletin for PKH26).

26. Houlihan, D.D. \& Newsome, P.N. Critical Review of Clinical Trials of Bone Marrow Stem Cells in Liver Disease. Gastroenterology. 135, 438-450 (2008).

27. Brusko, T.M., Hulme, M.A., Myhr, C.B., Haller, M.J., \& Atkinson, M.A. Assessing the In Vitro Suppressive Capacity of Regulatory T Cells. Immunol. Invest. 36, 607-628 (2007). 